\title{
Acknowledgments
}

THIS book would not be complete without acknowledging the individuals who helped make it a reality. First I am indebted to the scores of men and women pioneers in Hawaiian social research who developed the area of Japanese American studies. Scholars such as Yukiko Kimura, Bernhard Hormann, Andrew Lind, Katsumi Onishi, Jitsuichi Masuoka, Ernest Wakukawa, Romanzo Adams, Kiyoshi Ikeda, Louise Hunter, George Yamamoto, Take and Allan Beekman, and Harry H. L. Kitano have shared the conviction through their diverse works that the study of a relatively small ethnic group can provide creative inroads to understanding the American experience. The intellectual debt owed to them by any scholar in the field is beyond measure. In addition I must acknowledge the warm camaraderie of my colleagues, high school and community college teachers, research assistants, students, clergymen, community leaders, and businessmen with whom I have shared a myriad of insights and dialogues useful to illustrate an evolving Japanese American "local" lifestyle.

I wish also to thank Seymour Lutzky, Chairman of the American Studies Department at the University of Hawaii, whose continued support and sound advice have carried me through not only this publication but the demands ensuing from my work in the area of Japanese American studies. Special gratitude is also owed to Marcella Barcelona, Eileen Ebesu, and Sharon Uyeda, who conscientiously 


\section{xxiv ACKNOWLEDGMENTS}

helped in the preparation of this manuscript, to Janyce Blair for her editorial assistance, and to Keiji Kawakami for his perceptive comments.

Funding for this book was made possible by the Rockefeller Foundation through the American Studies Department at the University of Hawaii and the Juliette M. Atherton Trust through the Japanese American Research Center.

Lastly, I am thankful to Amy, my wife, for her warm understanding and positive encouragement. Through her I have learned a special beauty of the "local" spirit. 